\section{Molecular basis, diagnosis and clinical management of mucopolysaccharidoses}

\author{
Rossella Parini, ${ }^{1}$ Francesca Bertola, ${ }^{2}$ \\ Pierluigi Russo ${ }^{3}$ \\ 'UOS Malattie Metaboliche Rare, \\ Department of Pediatrics, Fondazione \\ MBBM, Azienda Ospedaliera San \\ Gerardo, University of Milano-Bicocca; \\ ${ }^{2}$ Consortium for Human Molecular \\ Genetics, University of Milano-Bicocca; \\ ${ }^{3}$ UO Department of Cardiology, Azienda \\ Ospedaliera San Gerardo, Monza, Italy
}

\section{Abstract}

Mucopolysaccharidoses (MPSs) are a group of hereditary, monogenic disorders caused by lysosomal storage of glycosaminoglycans. Their incidence as a group is between 1:25,000 and 1:45,000. At present 11 different enzyme deficiencies are know to be responsible of 7 similar but distinct diseases. The diagnosis is suspected clinically but must be confirmed through biochemical, enzymatic and molecular analysis. Prenatal diagnosis is feasible for each disease. The phenotype worsens with age, due to progressive storage, and mainly involves mucosal tissue, upper airways and lungs, bones and joints, central and peripheral nervous system, heart, liver, eye and ear. Any type of MPSs, is characterized by a wide variability of phenotype ranging from a severe fetal-neonatal disease to an attenuated form diagnosed in adult individuals. Recently new treatments, like hematopoietic stem cell transplantation and enzymatic replacement therapy, became available for many of these disorders entailing the urgency of early diagnosis to allow access to therapies. Thanks to therapies these patients have a longer life than in the past and this implies that also palliative treatments, of which the cardiological ones have a prominent part, must be undertaken diligently. The cardiologist may face, more frequently than expected, with the need to diagnose a patient with MPS who was not recognized by other specialists. The echocardiographic features of these patients are typical and may help in the clinical diagnosis. The future probably deserves to these disorders other new treatments or combination therapies, which might further improve prognosis of these diseases.

\section{Introduction}

The mucopolysaccharidoses (MPSs) are a group of monogenic disorders due to lysosomal storage of glycosaminoglycans (GAGs), previously called mucopolysaccharides. ${ }^{1}$ The deficiency of one of the enzymes participating in the GAGs degradation pathway causes progressive storage in the lysosomes and consequently in the cells and results in tissues and organs dysfunction. The damage is both direct or by activation of secondary and tertiary pathways among which a role is played by inflammation. ${ }^{2}$ The incidence of MPSs as a group is reported between 1:25000 and 1:45000. ${ }^{3}$ At present 11 different enzyme deficiencies are involved in MPSs producing 7 distinct clinical phenotypes ${ }^{1}$ (Table 1). ${ }^{4}$ Depending on the enzyme deficiency, the catabolism of dermatan sulphate, heparan sulphate, keratan sulphate, chondroitin sulphate, or hyaluronan may be impaired, singly or in combination. Diagnosis is suspected clinically and then confirmed by biochemical, enzymatic and molecular tests. For all the MPSs types prenatal diagnosis is available through enzymatic or molecular analysis.

In contrast to a recent past when there was only palliative treatment for these diseases, now many specific treatments like hematopoietic stem cell transplantation (HSCT) in selected cases (severe MPS I) and enzyme replacement therapy (ERT) for MPS I, II, and VI are available. ${ }^{5}$ These treatments are able to improve the clinical course of the disease mainly if started early. This brings along the responsibility for the clinician to recognize these diseases at the first signs to allow access to treatment before a severe damage has been established. In this respect pilot studies of newborn screening are ongoing. ${ }^{6}$ In recent years, availability of specific treatments, general improvement of palliative medical care and improvement of recognition of mild cases presenting later in life, have produced a growing number of adult MPSs patients in relatively good conditions who need to be cared after by adult services for metabolic diseases. Preparing the right setting for successful transition of these patients from pediatric to adult service is a difficult task that all the centers for MPSs in Europe are dealing with.

\section{Diagnosis of mucopolysaccharidoses and prenatal diagnosis}

Diagnosis of MPSs is suspected clinically on the basis of a number of clinical features (red flags; Table 2), 1,4,7,8 but it needs a laboratory confirmation. Urine GAGs analysis is a preliminary diagnostic test. There is a risk of false positive and negative results which is less frequent if a $24 \mathrm{~h}$ urine sample is collected and analyzed. There are patients with a normal GAGs urine concentration but an abnormal distribution of
Correspondence: Rossella Parini, Department of Pediatrics, San Gerardo Hospital, Via Pergolesi 33, 20900 Monza, Italy.

Tel. +39.039 .2333286 - Fax: +39.039 .2334364 .

E-mail: rossella.parini@unimib.it

Key words: mucopolysaccharidoses (MPS), heart, heart and MPS, genetics and MPS.

Acknowledgments: RP and PR acknowledge patients and their families and Drs. Andrea Imperatori and Lucia Boffi who collaborated in the clinical cardiological evaluation of MPSs patients. RP thanks Fondazione Pierfranco e Luisa Mariani of Milano for providing financial support for clinical assistance to metabolic patients and Mrs. Vera Marchetti, the secretary of the Metabolic Unit, for her very useful help in managing the patients.

Contributions: RP, PR, manuscript preparation and first draft; FB, first draft of paragraph What are mucopolysaccharidoses for the molecular biologist?; PR first draft of paragraph What are mucopolysaccharidoses for the cardiologist?; RP, other paragraphs and references writing. All authors reviewed the first draft and discussed the contained concepts.

Conflict of interests: RP has received honoraria, travel grants and/or research grants from Shire HGT, Genzyme Corporation Inc. and BioMarin; FB has received travel grants from Genzyme Corporation Inc.; PR has received travel grants from BioMarin.

Received for publication: 22 October 2012. Revision received: 1 January 2013

Accepted for publication: 11 January 2013.

This work is licensed under a Creative Commons Attribution NonCommercial 3.0 License (CC BYNC 3.0).

(C) Copyright R. Parini et al., 2013

Licensee PAGEPress, Italy

Cardiogenetics 2013; 3(s1):e2

doi:10.4081/cardiogenetics.2013.s1.e2

GAGs. The qualitative analysis is then suggested. Diagnosis is established by enzyme assay in cultured fibroblasts, leukocytes or serum. In clinical laboratories residual enzyme activity is not accurately quantified and is thus not a valid predictor of disease outcome. ${ }^{1}$ Conclusive diagnosis is performed with molecular analysis confirming results of enzyme activity and allowing an early prenatal diagnosis.

When a patient is diagnosed with a MPS disorder, genetic counseling is recommended. Genetic counseling can provide the family with information regarding the genetics, inheritance, and recurrence risks for the specific MPS condition in their family.

When the mutations in the family are known, prenatal diagnosis can be performed by molecu- 
lar analysis of tissue obtained by chorionic villus or amniocytes sampling. Enzymatic assay is often performed as well to guarantee the minor risk of misdiagnosis. If the mutations are not completely known the prenatal diagnosis may be performed with the enzymatic assay alone on chorionic villus sampling or amniocytes. ${ }^{1}$

\section{What are mucopolysaccharidoses for the molecular biologist?}

All MPSs have an autosomal recessive transmission with the exception of MPS type II (Hunter syndrome) that is X-linked. ${ }^{9}$

Most of MPSs genes have been identified and cloned in the 90 's. ${ }^{10}$ Only HSGNAT gene, responsible for MPS IIIC has been cloned later in $2006 .{ }^{10}$ Although mutations are frequently novel or private mutations, genotype-phenotype correlations are feasible in around $50 \%$ of cases when mutations identified are already docu- mented in previous studies and present in homozygous state or in heterozygous state with a second known severe mutation and when the clinical phenotype is established according to standardized scoring index of severity. Mutations resulting in large alterations of gene sequence, as nonsense mutations or frameshifts insertion/deletions, are generally identified in patients affected by the severe form of the disease. Missense and splicing mutations are sometime compatible with some enzymatic residual activity and then result in a wide range of phenotypes spanning the entire spectrum from severe to attenuated. ${ }^{1}$

The updating of mutations identified is available on Human Gene Mutation Database (http://www.hgmd.org).

\section{Mucopolysaccharidosis type I (MPS I)}

\section{IDUA gene maps to chromosome $4 p 16.3$}

The gene contains 14 coding exons and encodes for alfa-L-iduronidase, a polypeptide of 653 amino acids. ${ }^{11}$ So far, more than 180 mutations have been reported in MPS I patients spread along the entire coding and splicing regions without appreciable mutational hot spots. The two most common worldwide mutations are the nonsense p.W402X and p.Q70X associated to severe phenotype and much frequent in North Europe. p.G51D and p.P496R are specific Italian severe mutations whereas p.P533R, spread to Mediterranean countries, is associated to an intermediatesevere phenotype. ${ }^{12}$

\section{Mucopolysaccharidosis type II (MPS II)}

IDS gene maps to chromosome $\mathrm{Xq} 28$ and encodes for iduronate-2-sulphatase. Patients are hemizygous males or, very rarely, females due to autosomal-X chromosomal translocation or non-random X-chromosome inactivation, or in an only case homozygosis for a point mutation. ${ }^{13}$

More than 400 genetic alterations have been described along the 9 exons and splicing regions: the most frequent mutations occur-

Table 1. Nomenclature and classification of mucopolysaccharidoses.

\begin{tabular}{|c|c|c|c|}
\hline Defective enrayme & GAG storage material & Gene (localization) & Estimated incidence ${ }^{*}$ \\
\hline MPS I (Hurler, Hurler/Scheie, Scheie) & Dermatan sulphate, heparan sulphate & IDUA (4p16.3) & 1:84,000 \\
\hline MPS II (Hunter) Iduronate-2-sulphatase & Dermatan sulphate, heparan sulphate & IDS (Xq28) & $1: 196,000$ \\
\hline MPS IIIA (Sanfilippo A) & Heparan sulphate & SGSH (17q25.3) & $1: 92,000$ \\
\hline$N$-acetyl- $\alpha$-glucosaminidase & Heparan sulphate & $N A G L U(17 q 21.1)$ & $1: 157,000$ \\
\hline $\begin{array}{l}\text { Acetyl-CoA: } \alpha \text {-glucosamide } \\
N \text {-acetyltransferase }\end{array}$ & Heparan sulphate & HSGNAT (8p11.1) & $1: 714,000$ \\
\hline$N$-acetylglucosamine-6-sulphatas & Heparan sulphate & GNS (12q14) & $1: 1,000,000$ \\
\hline Galactose-6-sulphatase & Keratan sulphate, chondroitin-6-sulphate & GALNS (16q24.3) & $1: 131,000$ \\
\hline MPS IVB (Morquio B) & Keratan sulphate & GLB1 (3p21.33) & $1: 1,250,000$ \\
\hline MPS VI (Maroteaux-Lamy) & Dermatan sulphate & $A R S B(5 \mathrm{q} 11-\mathrm{q} 13)$ & $1: 120,000$ \\
\hline$\beta$-glucuronidase & $\begin{array}{l}\text { Dermatan sulphate, heparan sulphate, } \\
\text { chondroitin sulphate }\end{array}$ & GUSB (7q21.11) & $1: 588,000$ \\
\hline Hyaluronidase & Hyaluronan & HYAL1 (3p21.3-p21.2) & Only four cases reported \\
\hline
\end{tabular}

"Mean incidence estimated by Muenzer, 2011. ${ }^{4}$ MPS, mucopolysaccharidoses; GAG, glycosaminoglycans.

Table 2. Red flags: warning signs for early diagnosis of mucopolysaccharidoses.

\begin{tabular}{lcc} 
Most frequent signs and symptoms of onset & Most severe forms \\
Age of onset & $0-2$ years \\
Organomegaly & $\mathrm{Y}$ & $\mathrm{Y}$ \\
\hline Heart valve disease & $\mathrm{Y}$ \\
Hernias & $\mathrm{Y}($ gibbus!) \\
\hline Skeletal abnormalities & $\mathrm{N}$ \\
Joint contractures & $\mathrm{N}$ \\
\hline Eye disease & $\mathrm{N} / \mathrm{N}$ \\
\hline
\end{tabular}

Y, yes; N, no. 
ring at the Arg468 codon were identified in severe Hunter patients.

Due to the presence of a distal pseudogene (IDS2) containing sequences highly homologous to IDS gene, complete or partial gene deletions and large rearrangements are frequently identified, in about $10 \%$ of patients affected by the severe form. For this reason, sequencing of genomic DNA is often followed by cDNA analysis. ${ }^{14}$

\section{Mucopolysaccharidosis type III (MPS III)}

MPS III or Sanfilippo syndrome is classified in 4 subtypes deriving from 4 different enzyme defects involved in the degradation of the heparan sulphate. Four different genes encode each of these enzymes.

MPS IIIA is due to deficiency of the enzyme heparan $N$-sulphatase whose encoding gene is $S G S H$ gene, localized to chromosome $17 q 25.3$ and consisting in 8 exons. The over 100 mutations identified to date produce phenotype from severe to milder form. The most common mutation is the missense p. $\mathrm{R} 245 \mathrm{H}$ associated to severe form as well as p.S66W p.R74C, c.1080delC, and p.Q380R. p.S298P results instead in milder phenotypes. ${ }^{15,16}$

MPS IIIB (enzyme $N$-acetyl- $\alpha$-glucosaminidase) is caused by mutations along the 6 exons of the NAGLU gene mapped to chromosome $17 q 21.1$. Near 140 mutations have been identified so far, most of them occurring once or with low frequency. Only a small number of common mutations have been identified in MPS IIIB patients: the p.R279X and p.R626X associated to a severe phenotype. ${ }^{17}$

MPS IIIC disorder is caused by deficiency of acetyl-CoA: $\alpha$-glucosamide $N$-acetyltransferase caused by mutations in HSGNAT gene located at chromosome 8 p11.1 and composed by 18 exons. From its recent cloning in 2006, only 60 mutations have been identified. ${ }^{18}$

MPS IIID is the least common of the Sanfilippo syndromes. The defective enzyme is $N$-acetylglucosamine-6-sulphatase encoded by the gene GNS. It contains 14 exons and is mapped to chromosome 12q14. Only near 20 mutations have been identified so far, with an unexpected high proportion of large deletions compared to other MPS III subtypes. For this reason it is recommended to complete the molecular diagnosis with quantitative techniques if genomic analysis by sequencing results negative. ${ }^{19}$

\section{Mucopolysaccharidosis type IV (MPS IV)}

MPS IV or Morquio syndrome is classified in two forms: MPS IVA, due to the deficiency of $\mathrm{N}$-acetylgalactosamine 6-sulphate sulfatase (GALNS gene, chromosome 16q24.3) and MPS IVB, resulting from the deficiency of beta-galactosidase (GLB1 gene, chromosome 3 21.33). Both genes are fully characterized, consisting in 14 and 16 exons respectively. Of overall near 170 mutations, missense mutations are the most prevalent in GALNS gene and p.I113F, p.G301C and p.R386C are the most frequently identified in severe MPS IVA patients. ${ }^{20}$ Mutations in GLB1 gene are about 160 and give rise to two distinct lysosomal storage disorders, the MPS IVB and, in most cases, the GM1 gangliosidosis. MPS IVB patients are very rarely diagnosed and p.W273L is considered a common mutation among only a little set of 20 mutations recognized so far. $^{21}$

\section{Mucopolysaccharidosis type VI (MPS VI)}

MPS VI, also known as Maroteaux-Lamy syndrome, is caused by the deficiency of the arylsulfatase B. This lysosomal enzyme is codified by the $A R S B$ gene, comprising 8 exons, located to chromosome 5q11-q13. Most of the near 140 mutations identified so far are spread along $A R S B$ gene. Despite the high incidence of rare or private mutations, a panel of common mutations has been profiled: p.Y210C associated to the intermediate phenotype; p.L72R, p.R160X and p.R315Q associated to the severe phenotype. ${ }^{22}$

\section{Mucopolysaccharidosis type VII (MPS VII)}

MPS VII or Sly syndrome is characterized by the deficiency of the enzyme beta-glucuronidase coded by GUSB gene. The gene, located to chromosome 7q21.11, contains 12 exons. Among the next to 50 mutations identified to date, the most prevalent are the missense mutations and the p.L176F is the most representative associated to the attenuated phenotype.

Due to the presence of several pseudogenes, diagnostic techniques should be adopted first, to allow the screening of correct exons and splicing regions of GUSB gene, second, to identify novel possible large rearrangements. ${ }^{23}$

\section{Mucopolysaccharidosis type IX (MPS IX)}

MPS IX is the rarest form of MPS due to a deficiency of hyaluronidase enzyme implicated in hyaluronic acid degradation. The gene implicated is HYAL1 consists in 3 coding exons mapped to chromosome 3p21.31 where, together with HYAL2 and HYAL3, constitutes a multigene family for lysosomal hyluronidase genes. To date, only one patient diagnosed in 1996 and further three, belonging to a second family in 2011, have been described worldwide. ${ }^{24}$ Identification of other MPS IX patients will help to better define the clinical features and genotype phenotype correlation.

\section{What are \\ mucopolysaccharidoses \\ for the pediatrician?}

MPSs virtually affect all organs and tissues and show a progressive worsening with time. Most of the newborns appear healthy at birth and later, in the next months or years, they slowly develop the signs of the disease. Main signs are skeletal abnormalities, short stature, organomegaly, heart valve defects, hearing deficits, corneal clouding, retinopathy, glaucoma, brain involvement with progressive cognitive delay. Quality of life and life span are generally substantially reduced. ${ }^{4,7}$ Although similar, each type of MPSs has a peculiar phenotypic expression: MPS I is the prototype of MPSs and includes all the signs and symptoms listed above. MPS II is similar to MPS I but with a later clinical onset of somatic signs in the severe form and affecting only males. MPS VI is also affecting many organs and tissues and similar to MPS I, but these patients do never have frank cognitive delay. MPS III presents in the classic forms with very mild somatic involvement and fast and profound mental decline. MPS IV has a major skeletal involvement and short stature, with preserved cognition. Both MPS III and MPS IV generally have a slower progression of heart valve disease ${ }^{25}$ and survive longer than severe MPS I, II and VI phenotypes. These differences are at least partly due to the differences in the major accumulated substrate for each type of MPSs. For example those who have prevalent heparan sulphate excretion (MPS I, II, III), are known to be at risk of mental delay in the severe forms. ${ }^{1}$ Besides, within the same type of MPSs, the phenotypic spectrum is hugely variable, as a result of the different severity of mutations and overall genetic background of the single individual.

\section{Presenting signs and symptoms}

\section{Severe forms}

Most frequently present in the first 2-3 years of life with skeletal abnormalities (kyphosis with lumbar gibbus between 6 and 12 months in severe MPS I (Figure 1), and others after the first year of life in the other MPSs), often accompanied by dysmorphic facies (Figure 2A), organomegaly (Figure 2B), multiple hernias (inguinal, umbilical), abnormally frequent and severe upper airways infections, otitis and chronic rhinitis. Heart failure and severe valve disease in the first year of life are reported as the first presenting symptom in a minority of cases with MPS I, MPS VI and in a MPS III patient. ${ }^{25-27}$ In other patients, mainly with MPS III but also with MPS II, mental retardation at 23 years may be the only, or most evident, presenting sign. 


\section{Attenuated forms}

Attenuated forms have widely variable clinical presentations with different presenting signs at different ages, often one or few organs only clinically manifest the disease..$^{8,28}$ The most frequent signs of presentation are cardiac valve disease, eye disease, carpal tunnel syndrome and joints contractures.

\section{Long-term evolution}

The disease invariably gets on in years with slow worsening of the first symptoms and addition of others.

\section{Severe and intermediate forms}

Severe and intermediate forms show coarsening of facial appearance (prominent forehead, scaphocephaly, flat nasal bridge with broad nose, abnormalities of dental shape and position and macroglossia) (Figures 3 and 4), persistence and often relapse after surgery, of multiple hernias, severe ear, nose, throat (ENT) involvement with obstructive sleep apnea, noisy breathing, frequent middle ear infections and combined conductive-neurosensory hearing loss. All this is sustained by enlarged tongue, redundant mucosal tissue, hyperplasia of adenoids and tonsils, deformities of ossicles, narrow trachea (Figure 5), thickened vocal cord. Treatments with continuous positive airways pressure during the night, adenotonsillectomy, ventilating ear tubes insertion and hearing aids may be needed. ${ }^{5}$

Heart signs and symptoms also worse with time and often pharmacological treatment and/or valvular replacement become necessary.

Bone deformities become more and more evident (Figure 6): the term used to collectively indicate the typical skeletal deformities of MPSs is dysostosis multiplex. ${ }^{29}$ It includes short stature, scaphocephalic head, odontoid hypoplasia, anterior hypoplasia of lumbar vertebrae with kyphosis, spade-like hands, enlarged diaphyses of the long bones with irregular appearance of the metaphyses, small femoral heads and coxa valga, hip dislocation, short and thickened clavicles, oar-shaped ribs, tracheal deformities and joint contractures. Joint stiffness is a common and typical feature of all MPSs except for Morquio syndrome in which the joints tend to be hypermobile, secondary to ligamentous laxity. ${ }^{4}$ The major risk of instability of the hypoplastic odontoid process is run by MPS IV and in the order MPS I, MPS VI and MPS II. It can result in lifethreatening atlanto-axial subluxation. ${ }^{30}$ Spinal cord compression may also occur in the dorsal and lumbar spine. ${ }^{31}$ Magnetic resonance imaging of the cervical spine is recommended at the time of diagnosis and at regular intervals thereafter. Surgery to stabilize the spine by posterior fusion can be life saving. Both central and peripheral nervous system are affect-
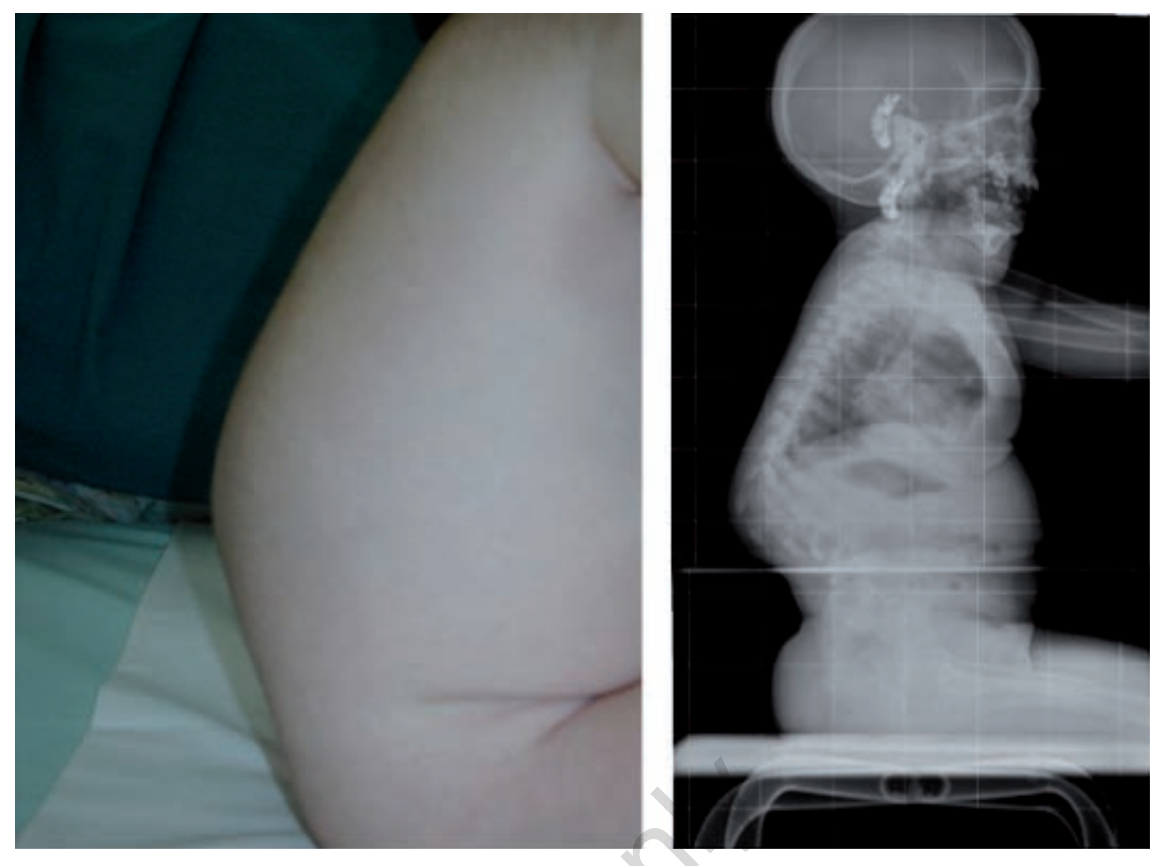

Figure 1. Early appearance of gibbus at 9 months of life and X-ray evolution after few years.
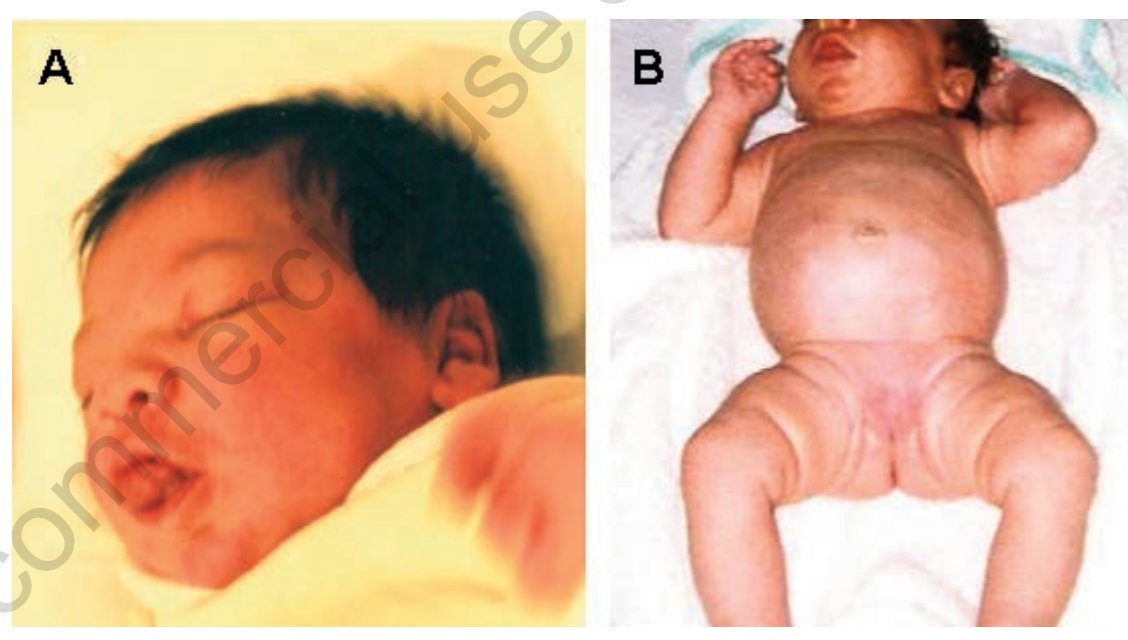

Figure 2. Coarse facies (A) and prominent abdomen (B) in a 2-month old infant affected by mucopolysaccharidosis type I Hurler.

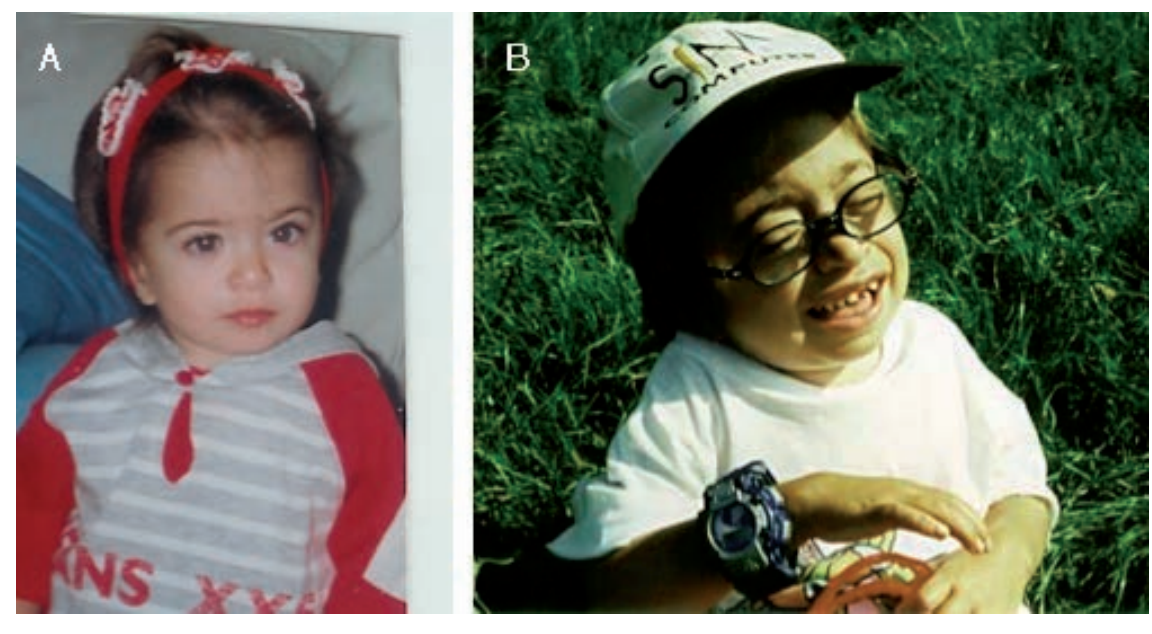

Figure 3. A and B) Same patient, affected by mucopolysaccharidosis type I H/S at 2 and 8 years old. 

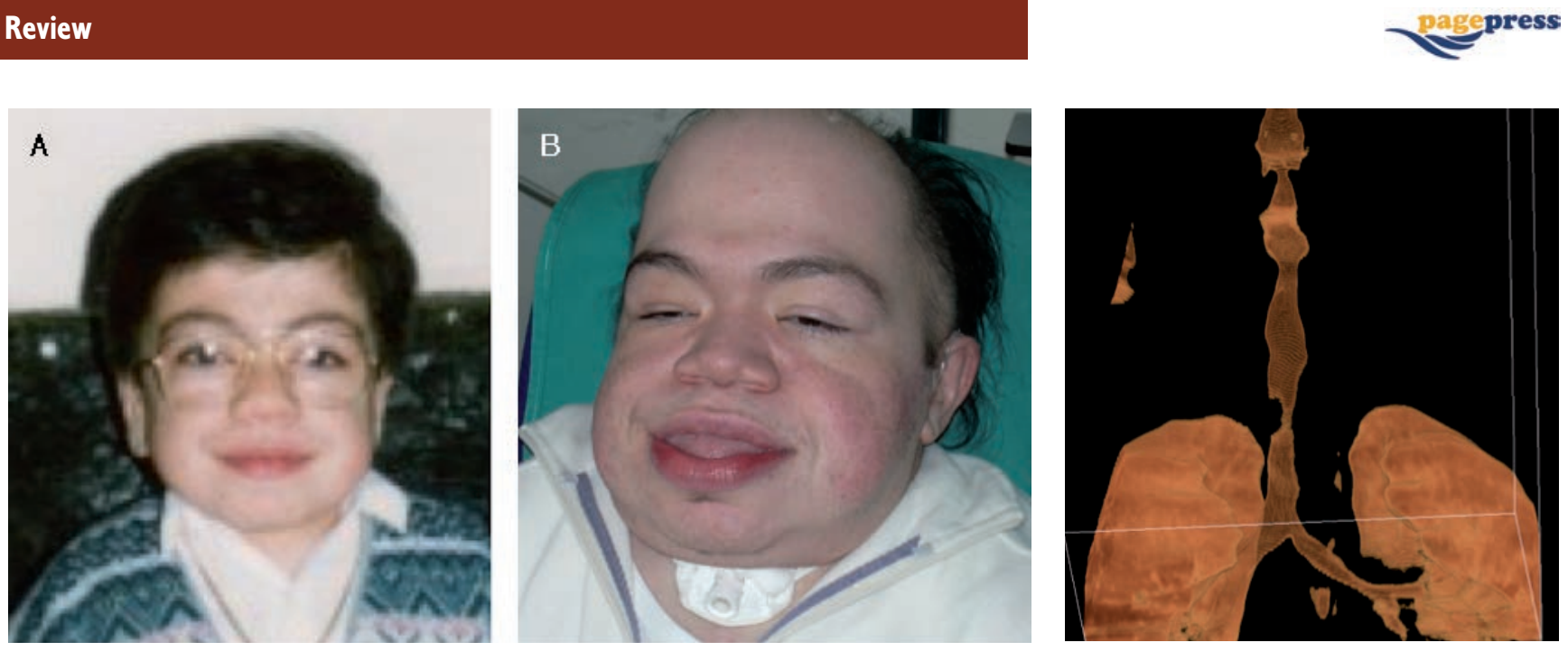

Figure 4. A and B) Progressive coarsening of facial appearance. Same patient with mucopolysaccharidosis type II at 12 and 26 years of age respectively.

Figure 5. Tracheal stenosis in mucopolysaccharidosis type II patient (multidetector computed tomography).

ed in the MPSs. Prominent perivascular spaces, hydrocephalus, brain atrophy, gliosis and white matter changes are common ${ }^{32,33}$ (Figure 7). The communicating hydrocephalus that occurs in MPSs is usually slowly progressive, with mild or absent clinical symptoms. Nerves entrapment syndromes, particularly of the carpal tunnel are common, but most patients lack typical symptoms until severe compression occurs. ${ }^{34}$ Seizures commonly occur in the oldest patients, and may be controlled by anti-epileptic drugs. ${ }^{35}$ Corneal clouding in MPS I, IV, VI and VII may lead to significant visual disability. Glaucoma and cataracts have been reported in MPS I and MPS VI and in MPS III and IV respectively. ${ }^{36}$

In severe forms of MPS I and MPS II, and in MPS III profound developmental delay is the rule after the first years of life. Hyperactivity with developmental delay is often the first sign of disease in MPS III patients who, as already mentioned, show very few somatic signs of MPS. This is particularly true for MPS IIIB ${ }^{37}$ (Figure 8).

\section{Attenuated forms}

In the attenuated forms progression of signs and symptoms is much slower than in the severe ones. These patients may have a presentation apparently limited to one only organ and are often seen by a specialist for years before reaching the diagnosis. ${ }^{8,28}$ They are often followed by rheumatologists, orthopedics and cardiologists. Ocular symptoms and signs are common in the attenuated forms that may develop corneal clouding, glaucoma and retinal degeneration resulting in peripheral vision and night blindness. These patients usually do not have severe cognitive delay. Progressive cord compression with resulting cervical

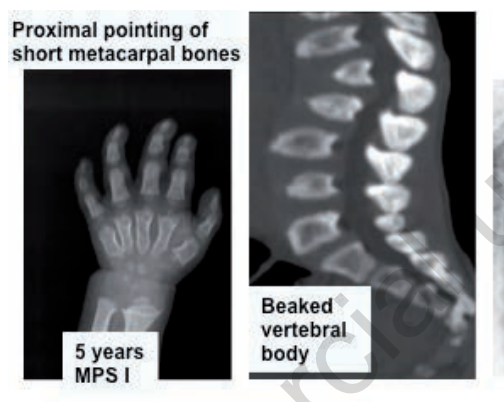

Prominent forehead, short neck
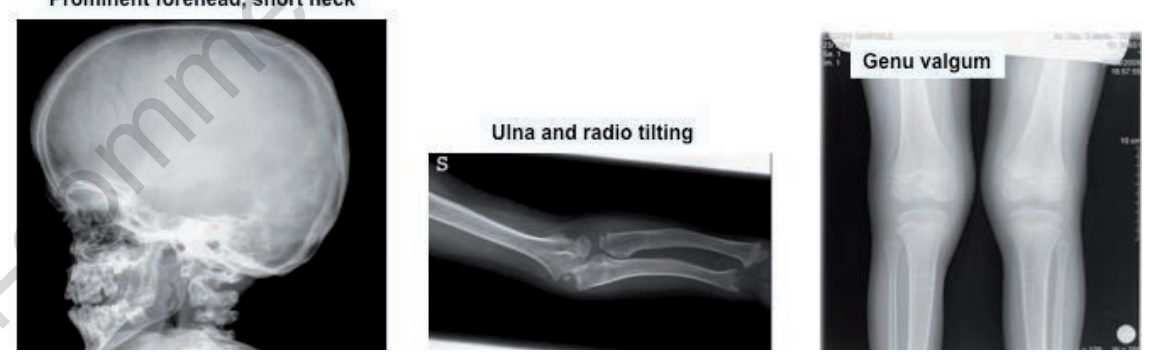

Figure 6. Generalized skeletal disease in mucopolysaccharidoses.
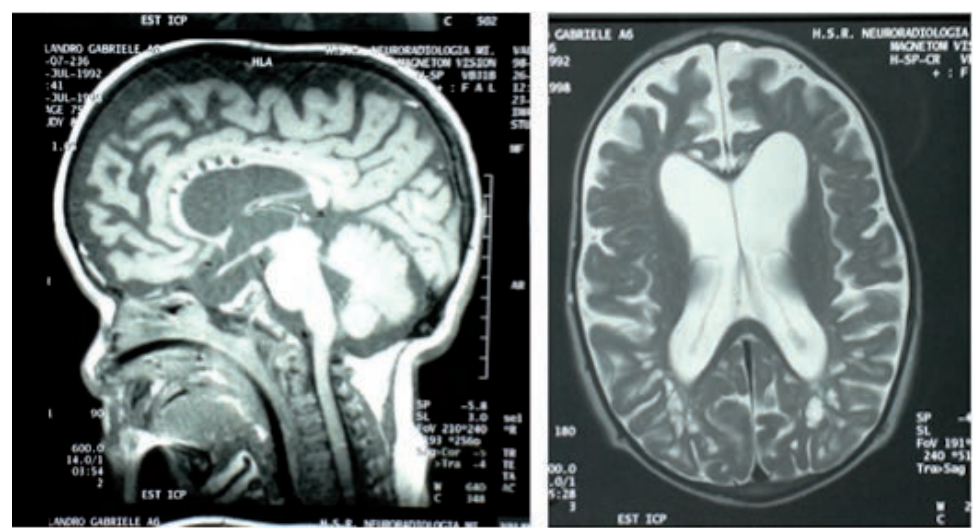

Figure 7. Brain atrophy, gliosis, white matter changes in 10-year old mucopolysaccharidosis type I Hurler patient receiving only palliative treatment. 
myelopathy due to dura mater thickening has been described in the mild forms of MPS I, II and VI. ${ }^{30,38,39}$

\section{Anesthesiological risk}

MPSs patients are exposed to a major risk of complications from general anesthesia and intubation. The same patients who are at major risk of atlanto-axial instability have major risk for anesthesia (MPS IV>MPS I and VI $>$ MPS II). The risk is also directly related to the severity of the disease and increases with age. Short neck, enlarged tongue, ENT abnormalities, vertebral malformations, and chest deformities, concur together to increase technical difficulties. Therefore when MPSs patients need surgery, they must be treated by a well informed and skilled anesthesiological team, aware of all risks of MPSs. ${ }^{40,41}$

\section{Specific treatments}

ERT is presently available for MPS I, MPS II and MPS VI and is currently under evaluation in a phase III international trial for MPS IV. ERT does not cross the blood-brain barrier and therefore is not effective in the brain. This is the main reason why HSCT is strongly recommended for severe MPS I. It is not recommended for severe MPS II and MPS III as well because results of HSCT in these diseases were discouranging. ${ }^{4}$ Besides the combined use of HSCT and ERT, other treatments for
MPSs are under evaluation: substrate degradation, ${ }^{42}$ site specific administration of ERT,43 chaperone administration ${ }^{44}$ and cell and genebased therapeutic approaches. ${ }^{45-49}$

\section{What are \\ mucopolysaccharidoses for the cardiologist?}

Cardiac involvement in MPSs is mainly represented by valve abnormalities, intramyocardial infiltration and accumulation (pseudohypertrophy) (Figure 9), endocardial fibroelastosis, narrowing of coronary arteries and, in

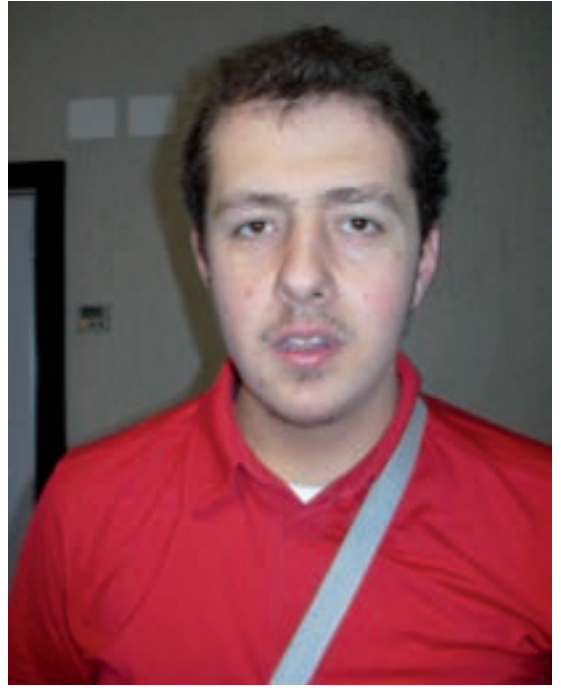

Figure 8. Adult mucopolysaccharidosis (MPS) type III B patient without typical facial features of MPS.

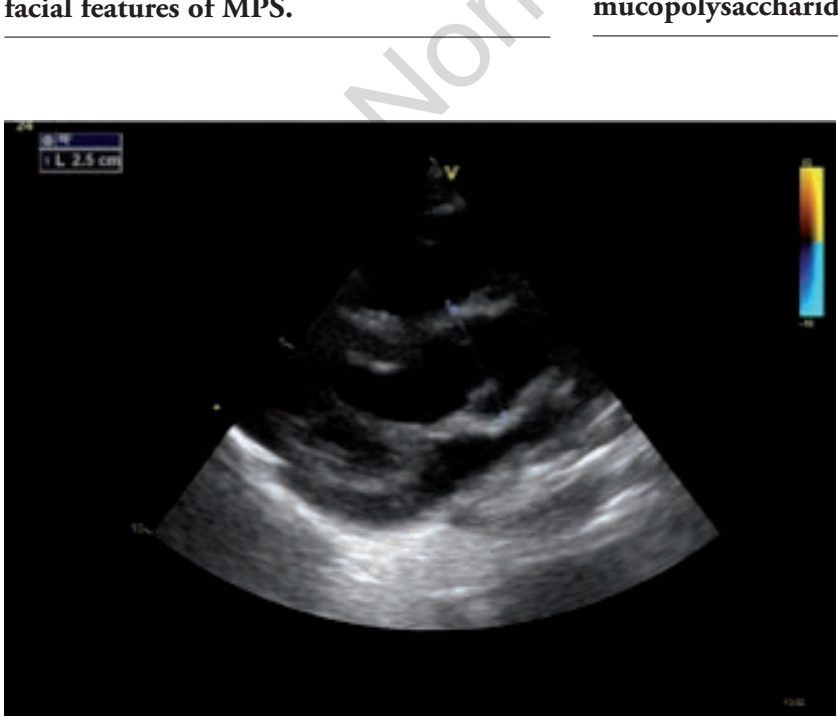

Figure 10. Mucopolysaccharidosis type $I$ in a 5-year old girl. Dilatation of the aortic root.

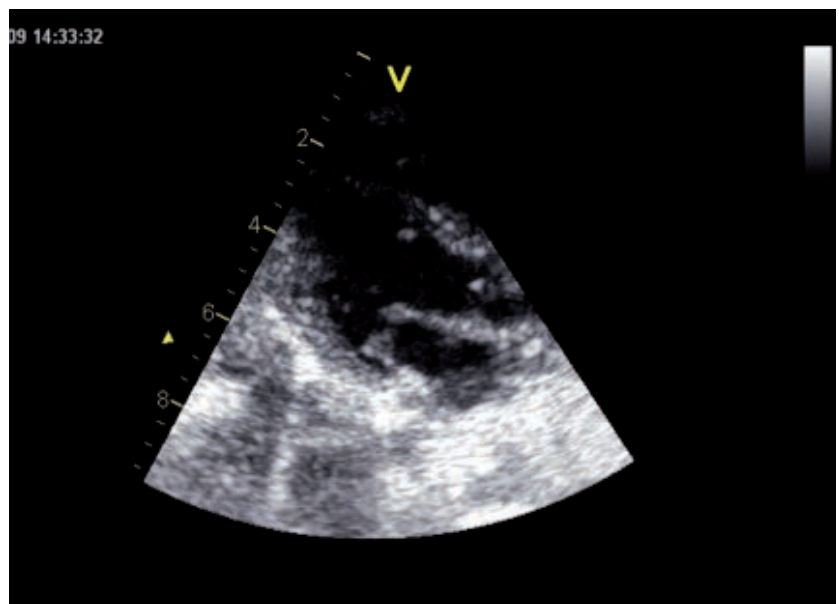

Figure 11. Mucopolysaccharidosis type $I$ in a 8-month old patient. Mitral valve involvement. 
rare cases, anomalies of the conduction tissue. Moreover, pulmonary hypertension may arise as a consequence of airways obstruction, deformity of the ribs or the accumulation of GAGs in the walls of pulmonary vessels. ${ }^{25,50-57}$ Thoracic and abdominal aorta arteriopathy (Figure 10) and hypertension may represent part of the clinical spectrum of the disease.${ }^{51}$ It is common opinion that the damage is more relevant and faster when dermatan sulphate is accumulated (type I, II, VI), because this GAG naturally prevails in the valves and the vessel's walls. ${ }^{58}$ Microscopically there is evidence of cytoplasmatic vacuoles in endothelial cells, myocytes and fibroblasts. ${ }^{59}$ There are fibroblasts that appear enlarged and foamy and are surrounded by collagen fibers. ${ }^{60}$ These, in the opinion of Braunlin et al. ${ }^{58}$ are engaged in attempted but ineffective valve repair.

\section{Valves abnormalities}

Valves abnormalities are the most frequent cardiac findings: mitral valve is often involved (Figure 11), less frequently aortic valve, and in some cases tricuspid (Figure 12) and pulmonary valve are involved too.

The valve damage appears to have a typical evolution, starting with valve insufficiency and progressing to stenosis during the disease course (Figure 13A-C). The natural history of the defect is probably sustained by deposition of GAGs secondarily associated to inflamation ${ }^{61}$ and eventually followed by fibrosis. In the very early phase the aspect of the valves is similar to a mixomatous valve with a redundancy of the thickened leaflets and consequent coaptation defect (Figure 13B). The pathogenesis of this precocious aspect has been attributed to the impaired degradation of the GAGs.62,63 Subsequently there is a defect of apposition (the first phase of normal valve closure in which the margins of the leaflets touch symmetrically between them) due to the irregular edge of the leaflets. This also happens very soon. With the progression of the disease, the leaflets become thickened and fibrous, often with a prevalent retraction of one of them and with an involvement of the subvalvular structure. In this phase, the apposition defect becomes the main mechanism of valve regurgitation. At the end, the calcification and the stiffness of the leaflets and the sub-valvular apparatus may occur and cause valve stenosis. ${ }^{64}$

Valve damage in MPS is quite typical, and differs from other common cardiological conditions, including mitral valve prolapse and rheumatic fever. Other lysosomal storage diseases like mucolipidosis type II and III (Figure 14) ${ }^{65}$ and Farber disease (Figure 15A and B) may show valve aspects similar to that of MPSs. In Fabry disease there may be mild valve damage but the main finding is the increased thickness of the ventricular walls. ${ }^{66}$ The comprehensive clinical evaluation of the patient, together with biochemical and molecular data will help in identifying the different diseases.

\section{Coronary artery disease}

A discrepancy has been reported between the relatively frequent absence of symptoms and the evidence of significant coronary involvement at postmortem examination. This is believed to be due to the antithrombotic activity of dermatan sulphate and heparan sulphate that avoid the formation of the thrombus in the stenotic coronaries. On the other hand, the clinical picture may arise at any age. A case of severe cardiac failure with fatal outcome in a ten months infant has recently been described. ${ }^{67}$ The autopsy showed the occlusion of the left main coronary artery. A minimal coronary involvement several years after hematopoietic stem cell transplantation has also been described. ${ }^{68}$

\section{Endocardial fibroelastosis}

It is a rare sign that essentially occurs in infants. Typically, at echocardiography examination the endocardium appears fibrotic with dense echogenity. ${ }^{69}$

\section{Aortic artery involvement}

Besides thoracic and abdominal aorta arteriopathy, ${ }^{51}$ dilatation and reduced elasticity of the ascending aorta has been described. It is probably related to the harmful effect of the GAGs on the formation of tropoelastin for abnormal content or abnormal structure of elastin. ${ }^{70}$

\section{tent or abnormal structure of elastin.}
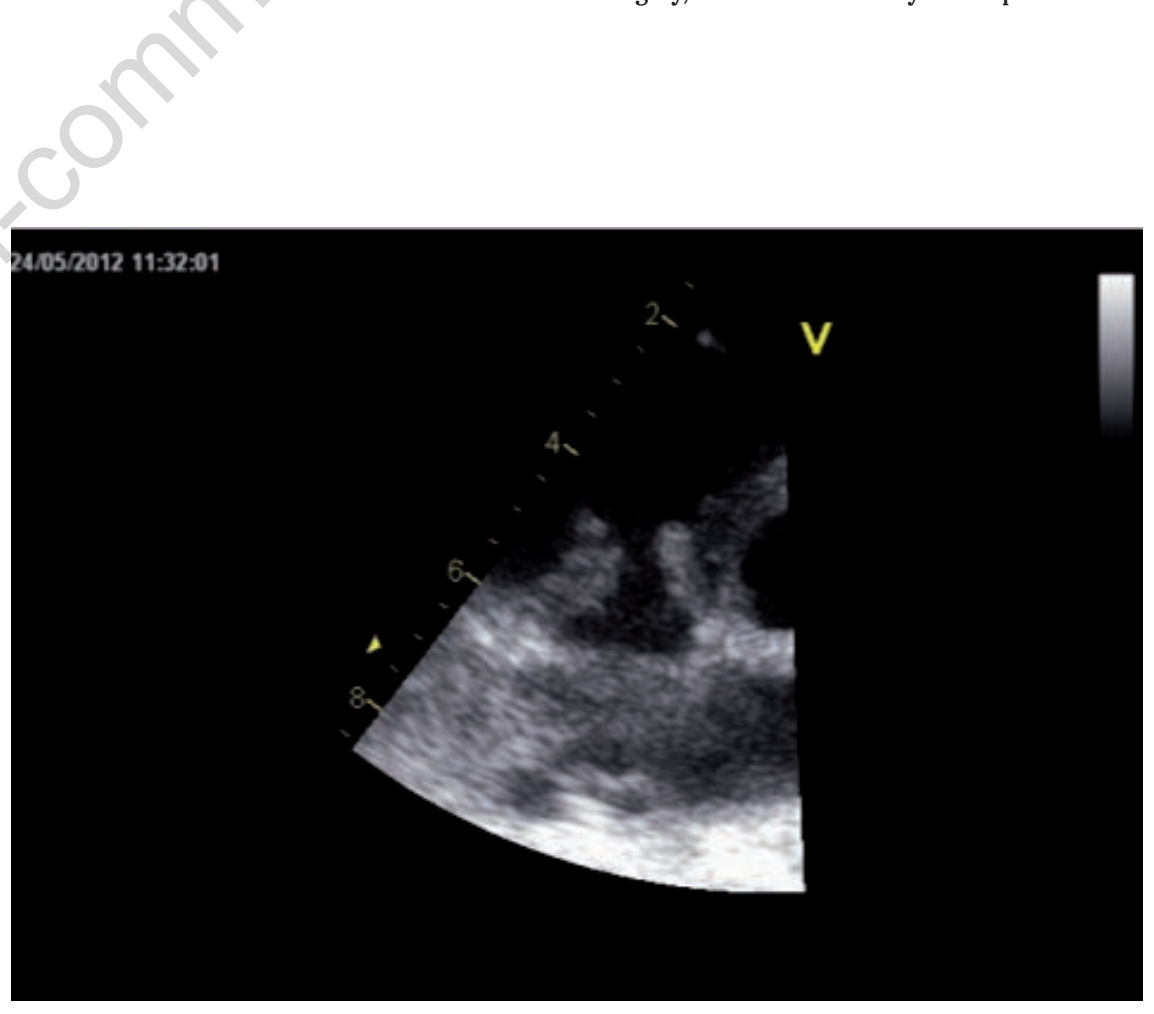

Figure 12. Tricuspid valve involvement in mucopolysaccharidosis type I.

\section{Tissue conduction anomalies} the development of atrioventricular block. ${ }^{71}$ Conduction abnormalities are rare in pediatric population, and might probably be prevented by enzyme replacement therapy or hematopoietic stem cell transplantation.

\section{Therapy for valve disease in mucopolysaccharidoses}

As suggested by ACC/AHA 2008 guidelines for the management of patients with valvular heart disease $^{72}$ there is no indication supporting the use of medications (i.e. ACE inhibitors or other vasodilatator drugs) in asymptomatic patients with various degrees of aortic or mitral regurgitation and preserved left ventricular function. In patients with severe valve regurgitation and left ventricular dilatation the use of diuretics and ACE-inhibitors is justified. Brain natriuretic peptide (BNP) and its precursor, NT-proBNP, may be of help to distinguish between cardiac and pulmonary dyspnoea, which is a frequent diagnostic dilemma in MPS. ${ }^{73}$ Although MPS patients have a high anesthesiological risk, ${ }^{40,41}$ the current surgical approach is to follow general guidelines for valve disease. However, the decision to perform a surgical intervention in these patients besides severity of valve disease, will also take into consideration the age and type of MPS, the current prognosis and specific risk for the single patient and the expectations of the family. If the decision is taken to perform surgery, it will be done only in hospitals where
There are some case reports documenting 

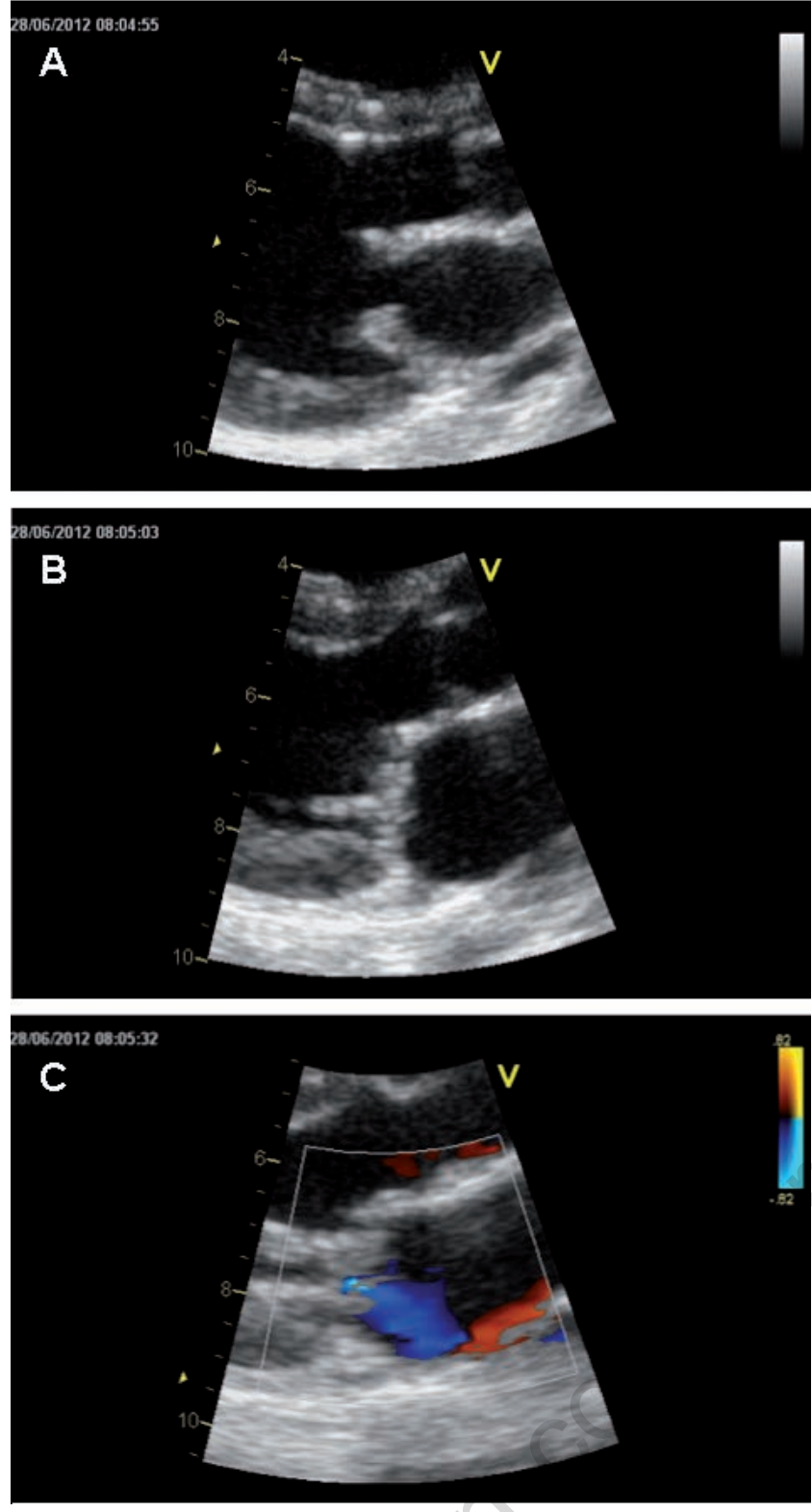

Figure 13. A) Mitral valve with thickened, retracted leaflets in mucopolysaccharidosis type II; B) Mitral valve defect of apposition and coaptation; C) Mitral regurgitation.

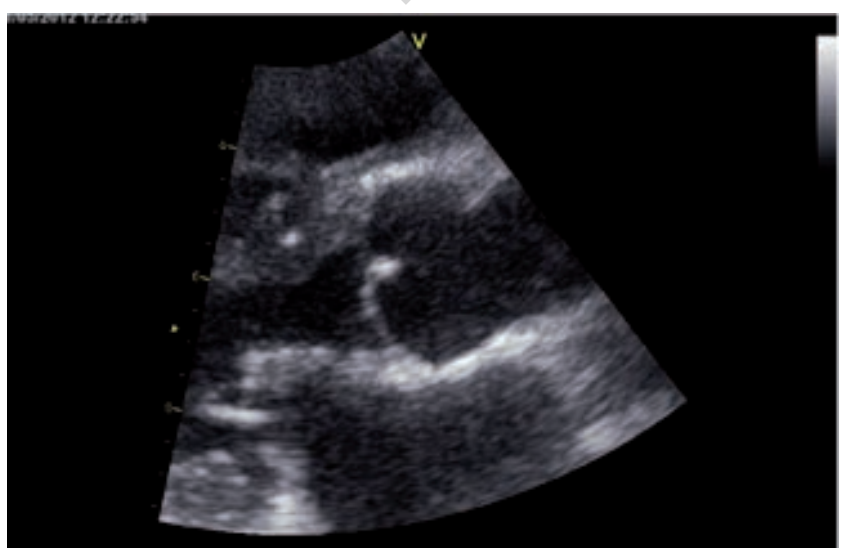

Figure 14. A 21-year old boy affected by mucolipidosis type III: the echocardiographic aspect of the aortic valve is similar to mucopolysaccharidosis valve disease.
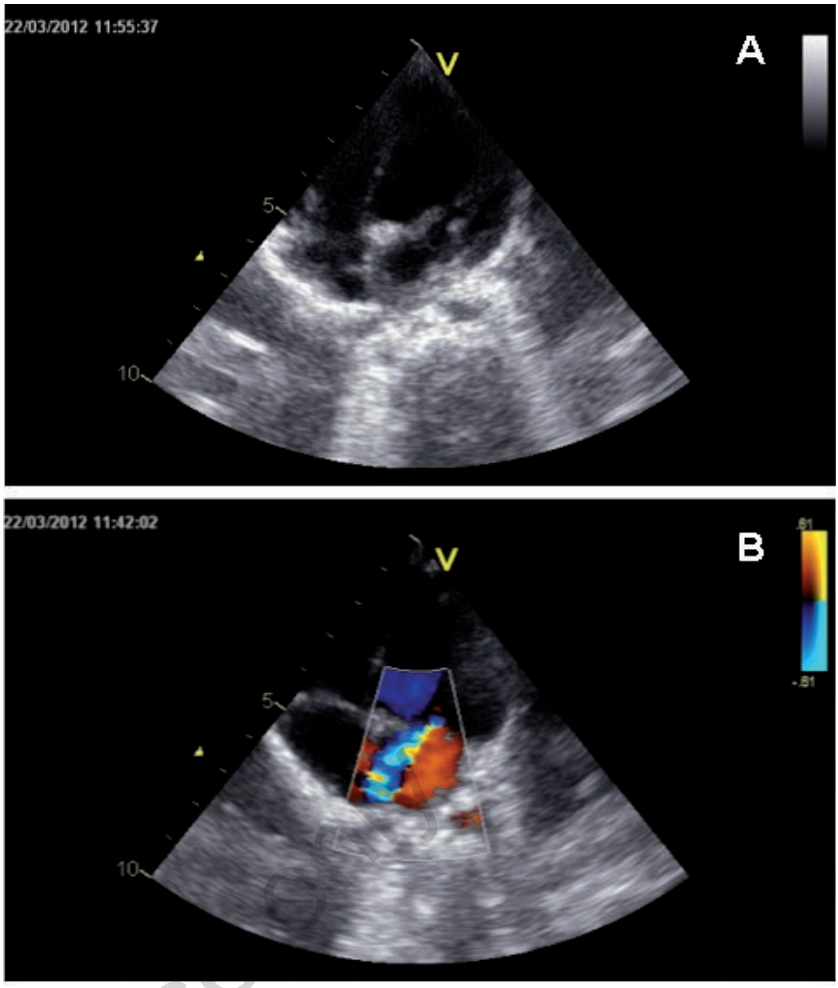

Figure 15. A) Farber syndrome. Mitral valve aspect in a 1-year old boy; B) Mitral valve regurgitation.
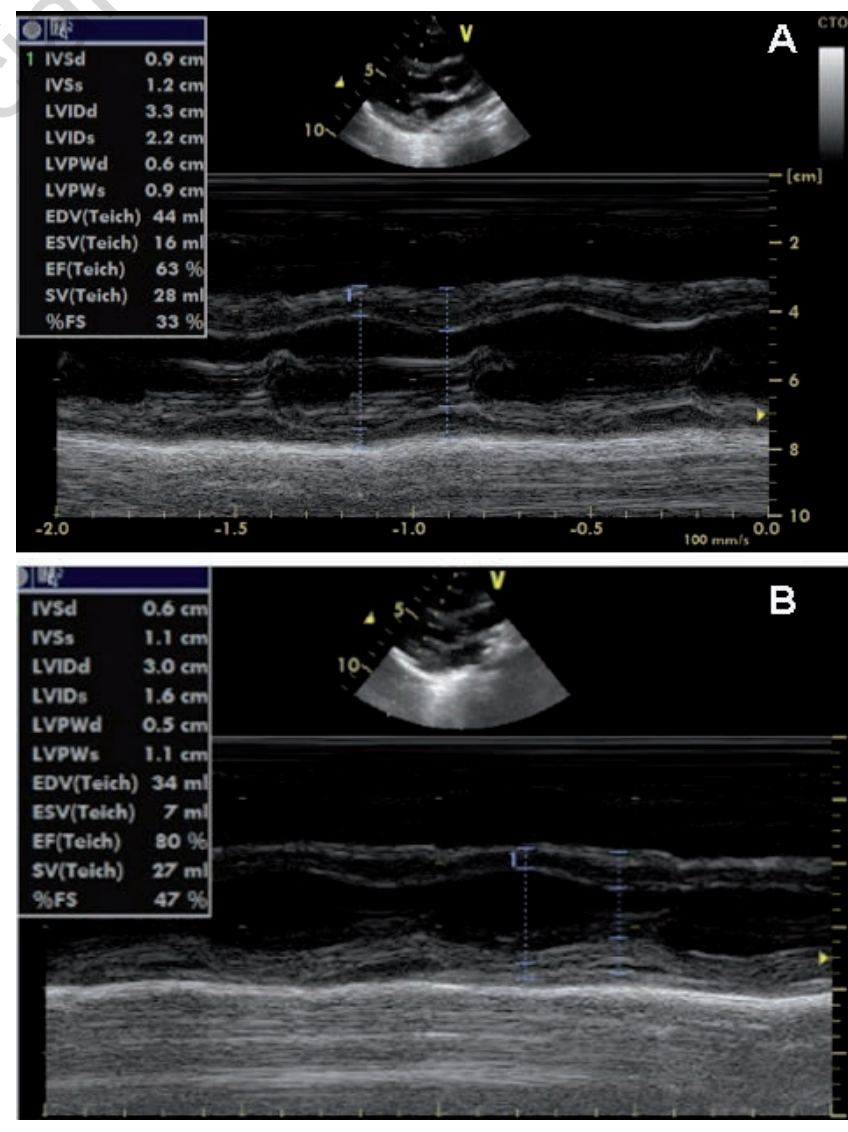

Figure 16. A) A 4-year old girl with mucopolysaccharidosis type I. Increased thickness of interventricular septum $(9 \mathrm{~mm})$; B) Same patient after 7-month enzymatic replacement therapy (interventricular septum $6 \mathrm{~mm}$ ). 
the anesthesiological team is well aware of risks and able to afford them. ${ }^{40,41}$ In the very young patients the policy is to postpone as much as possible the time of intervention, in order to prevent the need of a second prosthesis replacement later in follow-up.

Enzyme replacement therapy or hematopoietic stem cell transplantation are effective on pseudohypertrophy (Figure 16A and B) but not much on long term valve diseases. ${ }^{68,74}$ However the valvular damage could be potentially reversible or limited during the initial phase of accumulation of GAGs, before the progression toward the retraction and distortion of the leaflets occurs.

\section{Conclusions and future perspectives}

MPSs, both in the severe and attenuated forms, are devastating syndromes, substantially reducing quality and duration of life. In the last 20 years many achievements have been reached by the medical community in the knowledge of their genetic background and pathogenetic mechanisms. The better understanding of interand intracellular complex interactions, has allowed developing ERT for most of them. ERT has been shown to stabilize or attenuate progression of signs and symptoms of the disease. ${ }^{5}$ When started very early ERT seems probably able even to substantially reduce the skeletal burden in these patients. ${ }^{75,76}$ No effect has since been demonstrated on the eye and mainly on central nervous system involvement. Efforts are currently ongoing to set up treatments able to reach these sanctuaries: ERT local administration, different preparations of ERT, small molecules or cells or gene therapy reaching the CNS. At present the only treatment reaching the CNS and able to modify the cognitive evolution of patients is HSCT, a procedure known since around 30 years and used so far to treat many MPS I Hurler patients. ${ }^{77}$ Its harmfulness and related mortality have progressively slowed down with years and recently HSCT has also been proposed as a treatment for those Hurler/Scheie patients who slowly develop mental retardation. ${ }^{78}$ Unfortunately HSCT in Hunter (MPS II) and Sanfilippo (MPS III) syndromes did not obtain good results in the past and is then not recommended for these syndromes. ${ }^{77}$

Although their benefits, both ERT and HSCT are far from completely curing the MPSs. Therefore other promising treatments are currently under evaluation for a future use in humans, alone or in combination. However, as it is clear that, whatever the treatment is, it may be more effective if started at the onset of symptoms, neonatal screening for treatable MPSs disorders is ongoing in some regions of the world and results of pre-symptomatic diagnosis and early treatment will be available very soon. It is possible that they will even modify our convictions, for example about scarce efficacy of HSCT in MPS II and III.

Improvement of traditional care, HSCT and ERT have already modified survival and quality of life of MPSs patients: there are an increasing number of MPSs patients reaching adult age in good or at least discrete clinical conditions and expected to survive for a longer time than 20 years ago. Many organizational, ethical and medical reasons drive to shifting these kinds of patients to adult medical services. Often both clinicians and patients are not ready to this change and transition to adult service may be impossible or very hard. It is necessary that pediatric and adult centers for lysosomal diseases prepare transition for the next years, discussing procedures and modalities, together with hospital administrations and patients' organizations.

\section{References}

1. Neufeld EF, Muenzer J. The mucopolysaccharidoses. In: Scriver CR et al., eds. The metabolic and molecular bases of inherited disease. New York: McGraw Hill; 2001. pp. 3421-3452.

2. Clarke LA. Pathogenesis of skeletal and connective tissue involvement in the mucopolysaccharidoses: glycosaminoglycan storage is merely the instigator. Rheumatology (Oxford) 2011;50 Suppl 5:13-8.

3. Nelson J, Crowhurst J, Carey B, Greed L. Incidence of the Mucopolysaccharidoses in Western Australia. Am J Med Genet 2003;123A;310-3.

4. Muenzer J. Overview of the mucopolysaccharidoses. Rheumatology 2011;50 Suppl 5:4-12.

5. Valayannopoulos V, Wijburg FA. Therapy for the mucopolysaccharidoses. Rheumatology (Oxford) 2011;50 Suppl 5:49-59.

6. Nakamura K, Hattori K, Endo F. Newborn screening for lysosomal storage disorders. Am J Med Genet C Semin Med Genet 2011; 157:63-71.

7. Muenzer, J. The mucopolysaccharidoses: a heterogeneous group of disorders with variable pediatric presentations. J Pediatr 2004;144: 527-34.

8. Thomas JA, Beck M, Clarke JTR, Cox GF. Childhood onset of Scheie syndrome, the attenuated form of mucopolysaccharidosis I. J Inherit Metab Dis 2010;33:421-7.

9. Hopwood JJ, Bunge S, Morris, et al. Molecular basis of mucopolysaccharidosis type II: mutations in the iduronate-2-sulphatase gene. Hum Mutat 1993;2:435-42.

10. Coutinho MF, Lacerda L, Alves S. Glyco- saminoglycan storage disorders: a review. Biochem Res Int 2012;2012:471325.

11. Scott HS, Guo XH, Hopwood JJ, Morris CP. Structure and sequence of the human $\alpha-\mathrm{L}$ iduronidase gene. Genomics 1992; 13: 1311-3.

12. Bertola F, Filocamo M, Casati G, et al. IDUA mutational profiling of a cohort of 102 European patients with mucopolysaccharidosis type I: identification and characterization of 35 novel $\alpha$-L-iduronidase (IDUA) alleles. Hum Mutat 2011;32:E2189-210.

13. Scarpa M, Almássy Z, Beck M, et al. Mucopolysaccharidosis type II: European recommendations for the diagnosis and multidisciplinary management of a rare disease. Orphanet J Rare Dis 2011;6:72.

14. Lualdi S, Regis S, Di Rocco M, et al. Characterization of iduronate-2-sulfatase gene-pseudogene recombinations in eight patients with Mucopolysaccharidosis type II revealed by a rapid PCR-based method. Hum Mutat 2005;25:491-7.

15. Yogalingam G, Hopwood JJ. Molecular genetics of mucopolysaccharidosis type IIIA and IIIB: Diagnostic, clinical, and biological implications. Hum Mutat 2001;18: 264-81.

16. Valstar MJ, Neijs S, Bruggenwirth HT, et al. Mucopolysaccharidosis type IIIA: clinical spectrum and genotype-phenotype correlations. Ann Neurol 2010;68:876-87.

17. Beesley CE, Jackson M, Young EP et al. Molecular defects in Sanfilippo syndrome type B (mucopolysaccharidosis IIIB). J Inherit Metab Dis 2005;28:759-67.

18. Fedele A0, Hopwood JJ. Functional analysis of the HGSNAT gene in patients with mucopolysaccharidosis IIIC (Sanfilippo C Syndrome). Hum Mutat 2010;31:E1574-86.

19. Valstar MJ, Bertoli-Avella AM, Wessels MW, et al. Mucopolysaccharidosis type IIID: 12 new patients and 15 novel mutations. Hum Mutat 2010;31:E1348-60.

20. Tomatsu S, Montaño AM, Nishioka T, et al. Mutation and polymorphism spectrum of the GALNS gene in mucopolysaccharidosis IVA (Morquio A). Hum Mutat 2005; 26:500-12.

21. Caciotti A, Garman SC, Rivera-Colón Y, et al. GM1 gangliosidosis and Morquio B disease: an update on genetic alterations and clinical findings. Biochim Biophys Acta 2011;1812:782-90.

22. Karageorgos L, Brooks DA, Pollard A, et al. Mutational analysis of 105 mucopolysaccharidosis type VI patients. Hum Mutat 2007;28:897-903.

23. Tomatsu S, Montaño AM, Dung VC, et al. Mutations and polymorphisms in GUSB gene in mucopolysaccharidosis VII (Sly Syndrome). Hum Mutat 2009;30:511-9.

24. Imundo L, Leduc CA, Guha S, et al. A complete deficiency of Hyaluronoglucosa- 
minidase 1 (HYAL1) presenting as familial juvenile idiopathic arthritis. J Inherit Metab Dis 2011;34:1013-22.

25. Fesslovà V, Corti P, Sersale G, et al. The natural course and the impact of therapies of cardiac involvement in the mucopolysaccharidoses. Cardiol Young 2009;19:170-8.

26. Hirth A, Berg A, Greve G. Successful treatment of severe heart failure in an infant with Hurler syndrome. J Inherit Metab Dis 2007;30:820.

27. Hayflick S, Rowe S, Kavanaugh-McHugh A, et al. Acute infantile cardiomyopathy as a presenting feature of mucopolysaccharidosis VI. J Pediatr 1992;120:269-72.

28. Munoz-Roja MV, Bay L, Sanchez L. Clinical manifestations and treatment of mucopolysaccharidosis type I patients in Latin America as compared with the rest of the world J Inherit Metab Dis 2011;34:1029-37.

29. Gillespie JB, Siegling JA. Dysostosis multiplex. J Bone Joint Surg Am 1940;22:171-5.

30. White KK. Orthopaedic aspects of mucopolysaccharidoses. Rheumatology (Oxford) 2011;50 Suppl 5:26-33.

31. Kachur E, Del Maestro R. Mucopolysaccharidoses and spinal cord compression: case report and review of the literature with implications of bone marrow transplantation. Neurosurgery 2000;47:223-9.

32. Rasalkar DD, Chu WCW, Hui $\mathrm{J}$ et al. Pictorial review of mucopolysaccharidosis with emphasis on MRI features of brain and spine. Br J Radiol 2011;84:469-77.

33. Manara R, Priante E, Grimaldi M, et al. Brain and spine MRI features of Hunter disease: frequency, natural evolution and response to therapy. J Inherit Metab Dis 2011;34:763-80.

34. White K, Kim T, Neufeld JA. Clinical assessment and treatment of carpal tunnel syndrome in the mucopolysaccharidoses. J Pediatr Rehabil Med 2010;3:57-62.

35. Muenzer J, Beck M, Eng CM, et al. Multidisciplinary management of Hunter syndrome. Pediatrics 2009;124:e1228-39.

36. Summers CG, Ashworth JL. Ocular manifestations as key features for diagnosing mucopolysaccharidoses. Rheumatology (Oxford) 2011;50 Suppl 5:34-40.

37. Moog U, van Mierlo I, van Schrojenstein Lantman-deValk HM, et al. Is Sanfilippo type $B$ in your mind when you see adults with mental retardation and behavioral problems? Am J Med Genet C Semin Med Genet 2007;145C:293-301.

38. Modi M, Singla V, Khandelwal N, et al. Maroteaux-Lamy syndrome (mucopolysaccharidosis VI) presenting as familial myelopathy. Int J Neurosci 2011;121:337-40.

39. O'Brien DP, Cowie RA, Wraith JE. Cervical decompression in mild mucopolysaccharidosis type II (Hunter syndrome). Childs Nerv Syst 1997;13:87-90.
40. Walker RWM, Ellwood J. The Management of difficult intubation in children. Paediatr Anesth 2009;19 Suppl 1:77-87.

41. Ingelmo PM, Parini R, Grimaldi M, et al. Multidetector computed tomography (MDCT) for preoperative airway assessment in children with mucopolysaccharidoses. Minerva Anestesiol 2011;77:774-80.

42. Jakóbkiewicz-Banecka J, Piotrowska E, Gabig-Cimińska M, et al. Substrate reduction therapies for mucopolysaccharidoses. Curr Pharm Biotechnol 2011;12:1860-5.

43. Chen A, Dickson P. Intrathecal enzyme replacement therapy to treat spinal cord compression in mucopolysaccharidosis: Overview and rationale. J Pediatr Rehabil Med 2010;3:7-11.

44. de Ruijter J, Valstar MJ, Wijburg FA. Mucopolysaccharidosis type III (Sanfilippo Syndrome): emerging treatment strategies. Curr Pharm Biotechnol 2011;12:92330 .

45. Langford-Smith A, Wilkinson FL, LangfordSmith KJ, et al. Hematopoietic stem cell and gene therapy corrects primary neuropathology and behavior in mucopolysaccharidosis IIIA mice. Mol Ther 2012;20: 1610-21.

46. Smith LJ, Martin JT, O'Donnell P, et al. Effect of neonatal gene therapy on lumbar spine disease in mucopolysaccharidosis VII dogs. Mol Genet Metab 2012;107:145-52.

47. Visigalli I, Delai S, Politi LS, et al. Gene therapy augments the efficacy of hematopoietic cell transplantation and fully corrects mucopolysaccharidosis type I phenotype in the mouse model. Blood 2010;116: 5130-9.

48. Tomanin R, Zanetti A, Zaccariotto E, et al. Gene therapy approaches for lysosomal storage disorders, a good model for the treatment of mendelian diseases. Acta Paediatr 2012;101:692-701.

49. Pan D. Cell- and gene-based therapeutic approaches for neurological deficits in mucopolysaccharidoses. Curr Pharm Biotechnol 2011;12:884-96.

50. Nelson J, Shields MD, Mulholland HC. Cardiovascular studies in the mucopoly-saccharidoses. J Med Genet 1990;27:94-100.

51. Taylor DB, Blaser SI, Burrows PE, et al. Arteriopathy and coarctation of the abdominal aorta in children with mucopolysaccharidosis: imaging findings. Am J Roentgenol 1991;157:819-23.

52. Wippermann CF, Beck M, Schranz D, et al. Mitral and aortic regurgitation in 84 patients with mucopolysaccharidoses. Eur J Pediatr 1995;154:98-101.

53. Dangel JH. Cardiovascular changes in children with mucopolysaccharide storage diseases and related disorders - clinical and echocardiographic findings in 64 patients. Eur J Pediatr 1998;157:534-8.
54. Mohan UR, Hay AA, Cleary MA, et al. Cardiovascular changes in children with mucopolysaccharide disorders. Acta Paediatr 2002;91:799-804.

55. Rigante D, Segni G. Cardiac structural involvement in mucopolysaccharidoses. Cardiology 2002; 98:18-20.

56. Scarpa M, Barone R, Fiumara A et al. Mucopolysaccharidosis VI: the Italian experience. Eur J Pediatr 2009;168:1203-6.

57. Braunlin EA, Harmatz PR, Scarpa M, et al. Cardiac disease in patients with mucopolysaccharidosis: presentation, diagnosis and management. J Inherit Metab Dis 2011;34: 1183-97.

58. Braunlin E, Tolar J, Mackey-Bojack S, et al. Clear cells in the atrioventricular valves of infants with severe human muchopolysaccharidosis (Hurler syndrome) are activated valvular interstitial cells. Cardiovascular Pathol 2011;20:315-21.

59. Robbins S, Kumar V, Cotran R. Genetic disorders. In: Robins S, Kumar V, Kotran R, eds. Pathologic basis of disease. 4th edn. Philadelphia: W.B. Saunders Company; 1989. pp. 149-51.

60. Marwick TH, Bastian B, Hughes CF, Bailey BP. Mitral stenosis in the Maroteaux-Lamy syndrome: a treatable cause of dyspnoea. Postgrad Med J 1992;68:287-8.

61. Simonaro CM. Cartilage and chondrocyte pathology in the mucopolysaccharidoses: the role of glycosaminoglycan-mediated inflammation. J Pediatr Rehabil Med 2010; 3:85-8.

62. Grande-Allen KJ, Griffin BP, Ratliff NB, et al. Glucosaminoglycan profiles of mixomatous mitral leaflets and chorde parallel the severity of mechanical alterations. J AM Coll Cardiol 2003;42:271-7.

63. Rabkin E, Aikawa M, Stone JR, et al. Actived interstizial myofibroblasts express catabolic enzymes and mediate matrix remodeling in myxomatous heart valves. Circulation 2001;104:2525-32.

64. Tan CT, Shaff HV, Miller Jr FA, et al. Valvular heart disease in four patients with Maroteaux-Lamy syndrome. Circulation 1992;85:188-95.

65. Satoh Y, Sakamoto K, Fujibayashi Y, et al. Cardiac involvement in mucolipidosis. Importance of non invasive studies for detection of cardiac abnormalities. Jpn Heart J 1983;24:145-5.

66. Kampmann C, Linhart A, Baehner F, et al. Onset and progression of the AndersonFabry disease related cardiomyopathy. Int J Cardiol 2008;130:367-73.

67. van den Broek L, Baekx AP, Coolen H, et al. Fatal coronary artery disease in an infant with severe mucopolysaccharidosis tipe I. Pediatrics 2011;127:e1343-6.

68. Braunlin EA, Stauffer NR, Peters CH, et al. Usefulness of bone marrow transplanta- 
tion in the Hurler syndrome. Am J Cardiol 2003;92:882-6.

69. Fong LV, Menahem S, Wraith JE. Endocardial fibroelastosis in mucopolysaccharidosis type VI. Clin Cardiol 1987;10: 362-4.

70. Hinek A, Wilson SE. Impaired elastogenesis in Hurler disease. Dermatan sulfate accumulation linked to deficiency in elastin- binding protein and elastic fiber assembly. Am J Pathol 2000;156:925-38.

71. Hishitani T, Wakita S, Isoda T et al. Sudden death in Hunter syndrome caused by complete atrioventricular block. J Pediatr 2000;136:268-9.

72. Bonow R0, Carabello BA, Chatterjee K, et al. 2008 focused update incorporated into the ACC/AHA 2006 guidelines for the management of patients with valvular heart disease: a report of the American College of Cardiology/American Heart Association
Task Force on Practice Guidelines (Writing Committee to revise the 1998 guidelines for the management of patients with valvular heart disease). Endorsed by the Society of Cardiovascular Anesthesiologists, Society for Cardiovascular Angiography and Interventions, and Society of Thoracic Surgeons. J Am Coll Cardiol 2008;52:e1-142.

73. McMurray JJ, Adamopoulos S, Anker SD. ESC Guidelines for the diagnosis and treatment of acute and chronic heart failure 2012: The Task Force for the Diagnosis and Treatment of Acute and Chronic Heart Failure 2012 of the European Society of Cardiology. Developed in collaboration with the Heart Failure Association (HFA) of the ESC. Eur J Heart Fail 2012;14:803-69.

74. Braunlin EA, Berry JM, Whitley CB. Cardiac findings after enzyme replacement therapy for mucopolysaccharidosis type I. Am J Cardiol 2006;98:416-8.
75. Gabrielli 0, Clarke LA, Bruni S, Coppa GV. Enzyme-replacement therapy in a 5month-old boy with attenuated presymptomatic MPS I: 5-year follow-up. Pediatrics 2010;125:e183-7.

76. McGill JJ, Inwood AC, Coman DJ, et al. Enzyme replacement therapy for mucopolysaccharidosis VI from 8 weeks of age-a sibling control study. Clin Genet 2010;77: 492-8.

77. Rovelli AM. The controversial and changing role of haematopoietic cell transplantation for lysosomal storage disorders: an update. Bone Marrow Transplant 2008;41 Suppl 2:S87-9.

78. de Ru MH, Boelens JJ, Das AM, et al. Enzyme replacement therapy and/or hematopoietic stem cell transplantation at diagnosis in patients with mucopolysaccharidosis type I: results of a European consensus procedure. Orphanet J Rare Dis 2011;6:55. 